\title{
Desempenho produtivo de alevinos de tilápia-do-nilo alimentados com levedura e derivados
}

\author{
Hamilton Hisano(1), William Vicente Narváez-Solarte ${ }^{(2)}$, Margarida Maria Barros ${ }^{(3)}$ e Luiz Edivaldo Pezzato(3)
}

\begin{abstract}
(1)Embrapa Agropecuária Oeste, Rod. BR 163, Km 253,6, Caixa Postal 661, CEP 79804-970 Dourados, MS. E-mail: hhisano@cpao.embrapa.br (2)Universidad de Caldas, Dep. de Salud Animal, Calle 65 No. 26-10, Manizales, Colômbia. E-mail: wnarvaez@ucaldas.edu.co (3)Universidade Estadual Paulista, Fac. de Medicina Veterinária e Zootecnia, Dep. de Melhoramento e Nutrição Animal, Campus de Botucatu, Caixa Postal 560, CEP 18618-000 Botucatu, SP. E-mail: mbarros@fca.unesp.br, epezzato@fca.unesp.br
\end{abstract}

Resumo - O objetivo deste trabalho foi avaliar o desempenho produtivo e a composição químico-bromatológica do filé de tilápia-do-nilo alimentada com rações contendo levedura íntegra desidratada, levedura autolisada e parede celular. Rações práticas, isoprotéicas (32\% de proteína digestível) e isoenergéticas (3.200 kcal de energia digestível por $\mathrm{kg}$ ) suplementadas com levedura íntegra $(1,2 \mathrm{e} 3 \%)$, levedura autolisada $(1,2 \mathrm{e} 3 \%)$ e parede celular $(0,1 ; 0,2$ e $0,3 \%)$, e uma controle, sem ingredientes-teste, foram avaliadas. O delineamento experimental foi inteiramente casualizado, com dez tratamentos e quatro repetições. Peixes que receberam rações suplementadas com levedura e derivados apresentaram índice de desempenho produtivo superior ao controle. A suplementação da levedura autolisada proporcionou melhor resposta quanto ao ganho de peso $(\mathrm{p}<0,05)$. Não houve diferença na composição químico-bromatológica do filé, quando se compararam os contrastes entre totais de tratamento. A suplementação de levedura e derivados em rações para alevinos de tilápia-do-nilo melhora o desempenho produtivo, sem alterações na composição do filé, e entre os microingredientes avaliados, a levedura autolisada proporciona desempenho superior, quando utilizada entre 1,30 e 1,59\%.

Termos para indexação: Saccharomyces sp., Oreochromis niloticus, polissacarídeos.

\section{Growth performance of Nile tilapia fingerlings fed on yeast and yeast derivatives}

\begin{abstract}
The objective of this work was to assess growth perfomance and chemical-bromatological fillet composition of Nile tilapia fed on rations containing whole yeast, autolyzed yeast and yeast wall cell. Practical diets, isoproteic ( $32 \%$ of digestible protein), isoenergetic (3,200 kcal of digestible energy per $\mathrm{kg}$ ) and supplemented by whole yeast (1,2 and 3\%), autolyzed yeast (1,2 and 3\%) and yeast cell wall $(0.1,0.2$ and $0.3 \%)$, and a control diet without test ingredients were assessed. The experimental design was completely randomized, with ten treatments and four replicates. Animals fed on yeast and yeast derivatives supplemented diets showed enhanced growth performance compared to control. No difference on chemical-bromatological fillet composition was observed among contrast of totals of treatment. Yeast and yeast derivatives supplementation provided improvement on fish growth performance and inclusion of autolyzed yeast showed better growth performance when supplemented with 1.30 to $1.59 \%$.
\end{abstract}

Index terms: Saccharomyces sp., Oreochromis niloticus, polysaccharides.

\section{Introdução}

Os antibióticos e quimioterápicos podem ser utilizados na produção animal com finalidades terapêuticas, profiláticas e como agente promotor de crescimento. Principalmente neste último caso, é comum a utilização de dosagens subterapêuticas, que aumentam o risco de resistência de determinadas cepas de bactérias e podem comprometer uma parcela da microbiota normal do trato gastrintestinal, levando a diminuições consideráveis, ou até mesmo, sua dizimação (Mulder, 1993).
A possível resistência de bactérias patogênicas, que poderia ocasionar riscos consideráveis ao animal e principalmente à saúde humana, levou a União Européia a adotar como medida preventiva, a proibição de parte dos quimioterápicos utilizados como promotores de crescimento. Muitos países também estão seguindo esse exemplo e, como conseqüência, diversos produtos estão sendo avaliados como alternativa para substituí-los.

Atualmente a utilização de levedura íntegra, assim como derivados do seu processamento, tais como levedura autolisada, polissacarídeos da parede celular e 
nucleotídeos são recomendados para serem utilizados na composição das rações para organismos aquáticos. De acordo com Hisano et al. (2004), essas substâncias se destacam por sua biossegurança e fácil incorporação à mistura durante o processamento da ração. Além dessas características, a suplementação de levedura e derivados pode melhorar as respostas de desempenho produtivo, beneficiar o sistema imune não-específico e aumentar a resistência contra infecções bacterianas de algumas espécies de peixes (Sakai et al., 2001; Ortuño et al., 2002; Li \& Gatlin, 2003, 2004; Li et al., 2004).

Com a finalidade de compreender melhor as diversas funções das rações balanceadas para peixes tropicais, são necessários estudos com base na composição da levedura e seus co-produtos, e seu modo de atuação no organismo animal.

O objetivo deste trabalho foi avaliar o desempenho produtivo e a composição químico-bromatológica do filé de tilápia-do-nilo alimentada com rações contendo levedura íntegra desidratada, levedura autolisada e parede celular.

\section{Material e Métodos}

O experimento foi conduzido no Laboratório de Nutrição de Organismos Aquáticos (AquaNutri), da Fac. de Medicina Veterinária e Zootecnia, Universidade Estadual Paulista, Campus de Botucatu, SP.

Foram utilizados 240 alevinos de tilápia-do-nilo (Oreochromis niloticus) revertidos sexualmente para macho, com peso médio inicial de 2,22 $\pm 0,07 \mathrm{~g}$, os quais foram distribuídos aleatoriamente em 40 aquários circulares com volume de $250 \mathrm{~L}$ cada, numa densidade de estocagem de seis peixes por aquário, durante 80 dias.

Para manutenção dos parâmetros físico-químicos da água, os aquários foram reabastecidos por sistema de circulação de água com filtragem, por meio de biofiltro e com aquecimento controlado por termostato digital. A temperatura da água foi aferida diariamente às $8 \mathrm{e}$ $16 \mathrm{~h}, \mathrm{o} \mathrm{pH}$ e o teor de oxigênio dissolvido na água foram aferidos a cada sete dias, por meio de peagâmetro e oxímetro digitais, respectivamente.

As rações experimentais foram formuladas de acordo com a exigência nutricional para a espécie apresentada no National Research Council (1993) e com o conceito de proteína ideal, sendo isoprotéicas (32\% de proteína digestível), isocalóricas (3.200 kcal de energia digestível por $\mathrm{kg}$ ) e suplementadas com: levedura íntegra (LI), levedura autolisada (LA) e parede celular (PC), oriundas da levedura de destilaria de álcool de cana-de-açúcar, posteriormente processados e desidratados ("spray dried"). Estes produtos foram incluídos nos seguintes níveis: 1,2 e $3 \%$ para leveduras (íntegra ou autolisada) e $0,1,0,2$ e $0,3 \%$ para a parede celular, segundo recomendação do fabricante. A ração-controle foi caracterizada pela não utilização dos ingredientes em estudo (Tabela 1).

Os ingredientes utilizados nas rações experimentais foram moídos em moinho de facas, com diâmetro menor que $0,5 \mathrm{~mm}$. Posteriormente foram homogeneizados em misturador automático, e processados para obtenção de grânulos com os diâmetros de 2 e 3,5 mm, os quais foram utilizados nas fases inicial e final do experimento, respectivamente.

Os peixes foram alimentados ad libitum, seis vezes ao dia, às $8,10,12,14,16$ e 18h, numa proporção que possibilitou máxima ingestão com perda mínima de ração. Quinzenalmente foi realizada a limpeza dos aquários (sifonagem) para retirada de eventuais resíduos orgânicos. Todos os peixes foram pesados em balança de precisão $(0,01 \mathrm{~g})$, no final do experimento, sendo as pesagens antecedidas por um período de 24 horas de jejum.

$\mathrm{O}$ experimento foi conduzido em delineamento inteiramente casualizado, com dez tratamentos (rações) e quatro repetições. Foram avaliados os seguintes índices de desempenho produtivo: ganho de peso (GP), consumo de ração aparente $(\mathrm{C})$, conversão alimentar aparente (CA) e taxa de eficiência protéica (TEP). Após o período de avaliação do desempenho produtivo, foram coletados seis peixes por tratamento, os quais foram reunidos em três grupos que constituíram as repetições. Estes animais foram sacrificados por superdosagem de anestésico (benzocaína) e posteriormente eviscerados e filetados para determinação da composição corporal. Os filés foram acondicionados em sacos de plástico e congelados a $-20^{\circ} \mathrm{C}$. Após o descongelamento, os filés foram triturados e secados em estufa por 48 horas e moídos para obtenção de alíquotas para determinação dos teores de umidade (U\%), proteína bruta (PB\%), extrato etéreo (EE\%) e matéria mineral (MM\%), segundo a Association of Official Analytical Chemists (1990).

Os dados de desempenho produtivo e composição químico-bromatológica dos filés foram submetidos à análise de variância (Stell \& Torrie, 1984). A análise incluiu os contrastes ortogonais entre totais de tratamentos - levedura íntegra, levedura autolisada e parede celular -, bem como a análise de polinômios 
ortogonais para estimativa do nível ótimo de suplementação. Todas as análises foram realizadas utilizando-se o procedimento General Linear Model do SAS Institute (1985).

\section{Resultados e Discussão}

Os valores médios e o desvio-padrão da temperatura, oxigênio dissolvido e $\mathrm{pH}$ da água dos aquários durante $\mathrm{o}$ período experimental foram de $26,0 \pm 0,7^{\circ} \mathrm{C}$, $7,1 \pm 0,3 \mathrm{mg} \mathrm{L}^{-1} \mathrm{e} 7,3 \pm 0,2$, respectivamente. Esses valores estão dentro da faixa de conforto para tilápias, recomendado por Popma \& Green (1990).

Os valores médios de GP, quando submetidos à análise de variância, apresentaram diferenças $(\mathrm{p}<0,01)$ para tratamentos (Tabela 2). O desdobramento dos graus de liberdade dos tratamentos, na análise de variância, formado pelos contrastes ortogonais entre totais de tratamentos (LI, LA e PC) demonstrou que o GP dos peixes cujas rações continham LA diferiu do grupo que recebeu ração contendo LI $(\mathrm{p}<0,05)$ e também do grupo que recebeu ração contendo $\mathrm{PC}(\mathrm{p}<0,01)$. Entretanto, não houve diferença significativa $(\mathrm{p}>0,05)$ quanto ao GP entre os grupos LI e PC. As melhores respostas de GP, em ordem decrescente, foram observadas em peixes alimentados com as rações contendo LA, LI e PC.

Com base nesses resultados, estimou-se o nível ótimo de suplementação, quando significativo, por meio da análise de polinômios ortogonais. Observou-se efeito polinomial quadrático $(\mathrm{p}<0,05)$, expresso pela equação $\mathrm{Y}=61,64+11,69 \mathrm{x}-3,01 \mathrm{x}^{2}\left(\mathrm{R}^{2}=0,74\right)$, com o maior GP apresentado pela inclusão de $1,94 \%$ de LI.

Em relação aos resultados de GP dos peixes que foram alimentados com as rações contendo LA, houve efeito polinomial quadrático $(\mathrm{p}<0,01)$, expresso pela

Tabela 1. Composição porcentual das rações experimentais (matéria original).

\begin{tabular}{|c|c|c|c|c|c|c|c|c|c|c|}
\hline \multirow[t]{2}{*}{ Ingrediente (\%) } & \multirow[t]{2}{*}{ Controle } & \multicolumn{3}{|c|}{ Levedura íntegra } & \multicolumn{3}{|c|}{ Levedura autolisada } & \multicolumn{3}{|c|}{ Parede celular } \\
\hline & & $1 \%$ & $2 \%$ & $3 \%$ & $1 \%$ & $2 \%$ & $3 \%$ & $0,1 \%$ & $0,2 \%$ & $0,3 \%$ \\
\hline Farelo de soja & 66,00 & 66,00 & 65,50 & 65,00 & 66,00 & 65,50 & 65,00 & 66,00 & 66,00 & 66,00 \\
\hline Fubá de milho & 17,10 & 16,10 & 15,60 & 15,10 & 16,10 & 15,60 & 15,10 & 17,00 & 16,90 & 16,80 \\
\hline Farelo de trigo & 8,40 & 8,40 & 8,40 & 8,40 & 8,40 & 8,40 & 8,40 & 8,40 & 8,40 & 8,40 \\
\hline Levedura íntegra & - & 1,00 & 2,00 & 3,00 & - & - & - & - & - & - \\
\hline Levedura autolisada & - & - & - & - & 1,00 & 2,00 & 3,00 & - & - & - \\
\hline Parede celular & - & - & - & - & - & - & - & 0,10 & 0,20 & 0,30 \\
\hline DL-metionina & 0,36 & 0,36 & 0,36 & 0,36 & 0,36 & 0,36 & 0,36 & 0,36 & 0,36 & 0,36 \\
\hline Fosfato bicálcico & 3,90 & 3,90 & 3,90 & 3,90 & 3,90 & 3,90 & 3,90 & 3,90 & 3,90 & 3,90 \\
\hline Óleo de soja & 3,59 & 3,59 & 3,59 & 3,59 & 3,59 & 3,59 & 3,59 & 3,59 & 3,59 & 3,59 \\
\hline Suplemento vit. e min. . $^{(1)}$ & 0,50 & 0,50 & 0,50 & 0,50 & 0,50 & 0,50 & 0,50 & 0,50 & 0,50 & 0,50 \\
\hline Vitamina $C^{(2)}$ & 0,03 & 0,03 & 0,03 & 0,03 & 0,03 & 0,03 & 0,03 & 0,03 & 0,03 & 0,03 \\
\hline $\mathrm{NaCl}$ & 0,10 & 0,10 & 0,10 & 0,10 & 0,10 & 0,10 & 0,10 & 0,10 & 0,10 & 0,10 \\
\hline $\mathrm{BHT}^{(3)}$ & 0,02 & 0,02 & 0,02 & 0,02 & 0,02 & 0,02 & 0,02 & 0,02 & 0,02 & 0,02 \\
\hline Total & 100,0 & 100,0 & 100,0 & 100,0 & 100,0 & 100,0 & 100,0 & 100,0 & 100,0 & 100,0 \\
\hline \multicolumn{11}{|l|}{ Composição (\%) } \\
\hline $\mathrm{PD}(\%)^{(4)}$ & 32,00 & 32,00 & 32,00 & 32,00 & 32,00 & 32,00 & 32,00 & 32,00 & 32,00 & 32,00 \\
\hline $\mathrm{ED}\left(\mathrm{kcal} \mathrm{kg}^{-1}\right)^{(5)}$ & 3200 & 3200 & 3200 & 3200 & 3200 & 3200 & 3200 & 3200 & 3200 & 3200 \\
\hline $\mathrm{FB}(\%)$ & 5,00 & 5,00 & 5,00 & 5,00 & 5,00 & 5,00 & 5,00 & 5,00 & 5,00 & 5,00 \\
\hline $\operatorname{EED}(\%)^{(6)}$ & 3,89 & 3,90 & 4,01 & 3,71 & 3,88 & 3,76 & 3,77 & 3,96 & 4,12 & 3,90 \\
\hline Cálcio (\%) & 1,20 & 1,20 & 1,20 & 1,20 & 1,20 & 1,20 & 1,20 & 1,20 & 1,20 & 1,20 \\
\hline Pdisp. $(\%)^{(7)}$ & 0,70 & 0,70 & 0,70 & 0,70 & 0,70 & 0,70 & 0,70 & 0,70 & 0,70 & 0,70 \\
\hline Metionina (\%) & 0,60 & 0,60 & 0,60 & 0,60 & 0,60 & 0,60 & 0,60 & 0,60 & 0,60 & 0,60 \\
\hline Treonina $(\%)$ & 1,00 & 1,00 & 1,00 & 1,00 & 1,00 & 1,00 & 1,00 & 1,00 & 1,00 & 1,00 \\
\hline Lisina $(\%)$ & 1,70 & 1,70 & 1,70 & 1,70 & 1,70 & 1,70 & 1,70 & 1,70 & 1,70 & 1,70 \\
\hline
\end{tabular}

(1) Suplemento vitamínico e mineral (Supre Mais): nível de garantia por kg do produto: vit. A: 1.200.000 UI; vit. D3: 200.000 UI; vit. E: $12.000 \mathrm{mg}$; vit. K3: $2.400 \mathrm{mg}$; vit. B1: $4.800 \mathrm{mg}$; vit. B2: $4.800 \mathrm{mg}$; vit. B6: $4.000 \mathrm{mg}$; biotina: $48 \mathrm{mg}$; colina: $65.000 \mathrm{mg}$; niacina: $24.000 \mathrm{mg}$; Fe: $10.000 \mathrm{mg}$; Cu: $600 \mathrm{mg}$; Mn: $4.000 \mathrm{mg}$; Zn: $6.000 \mathrm{mg}$; I: $20 \mathrm{mg}$; Co: $2 \mathrm{mg}$ e Se: $20 \mathrm{mg}$. (2)Sal cálcica 2-monofosfato de ácido ascórbico (42\% de princípio ativo). ${ }^{(3)}$ Butil hidroxi tolueno (antioxidante). ${ }^{(4)}$ Proteína digestível. ${ }^{(5)}$ Energia digestível. ${ }^{(6)}$ Extrato etéreo digestível; valores calculados de acordo com Pezzato et al. (2002) e Hisano (2005). ${ }^{(7)}$ Fósforo disponível; valores calculados com base nos valores apresentados por Gonçalves (2003). 
equação $Y=63,93+19,62 x-6,14 x^{2}\left(R^{2}=0,82\right)$, com o maior GP apresentado pela inclusão de $1,59 \%$.

Os diferentes níveis de inclusão de PC na ração resultaram em GP dos peixes semelhantes. Embora não tenham existido diferenças entre as médias de GP, observou-se que os peixes que receberam as rações contendo 0,3\% apresentaram tendência linear crescente de maior GP. Possivelmente, a inclusão de níveis maiores que $0,3 \%$ de $P C$ resultaria em respostas ainda mais positivas.

Tabela 2. Média do ganho de peso (GP), consumo alimentar aparente $(\mathrm{C})$, conversão alimentar aparente (CA) e taxa de eficiência protéica (TEP) de tilápia-do-nilo alimentada com rações suplementadas com diferentes níveis de levedura íntegra (LI), levedura autolisada (LA) e parede celular (PC) ${ }^{(1)}$.

\begin{tabular}{|c|c|c|c|c|}
\hline Fonte de variação & $\mathrm{GP}(\mathrm{g})$ & $\mathrm{C}(\mathrm{g})$ & CA & TEP \\
\hline & \multicolumn{4}{|c|}{ Levedura íntegra } \\
\hline Controle & 63,69 & 81,10 & 1,28 & 2,42 \\
\hline LI $1 \%$ & 64,17 & 86,30 & 1,35 & 2,27 \\
\hline LI $2 \%$ & 79,12 & 106,06 & 1,34 & 2,27 \\
\hline LI $3 \%$ & 67,55 & 90,46 & 1,34 & 2,26 \\
\hline Teste F & $* *$ & $* *$ & ns & ns \\
\hline \multirow[t]{2}{*}{$\mathrm{CV}(\%)$} & 6,02 & 8,22 & 6,46 & 6,71 \\
\hline & \multicolumn{4}{|c|}{ Levedura autolisada } \\
\hline Controle & 63,69 & 81,10 & 1,28 & 2,42 \\
\hline LA $1 \%$ & 78,14 & 95,85 & 1,23 & 2,49 \\
\hline LA $2 \%$ & 77,89 & 93,01 & 1,19 & 2,55 \\
\hline LA $3 \%$ & 67,76 & 89,55 & 1,33 & 2,29 \\
\hline Teste F & $* *$ & $* *$ & $*$ & $* *$ \\
\hline \multirow[t]{2}{*}{$\mathrm{CV}(\%)$} & 7,70 & 6,85 & 4,15 & 3,79 \\
\hline & \multicolumn{4}{|c|}{ Parede celular } \\
\hline Controle & 63,69 & 81,10 & 1,28 & 2,42 \\
\hline PC $0,1 \%$ & 68,84 & 86,19 & 1,25 & 2,53 \\
\hline PC $0,2 \%$ & 66,83 & 83,61 & 1,25 & 2,53 \\
\hline PC $0,3 \%$ & 70,55 & 86,38 & 1,22 & 2,57 \\
\hline Teste F & ns & ns & ns & $\mathrm{ns}$ \\
\hline $\mathrm{CV}(\%)$ & 8,52 & 8,16 & 5,30 & 5,20 \\
\hline \multicolumn{5}{|c|}{ Teste F } \\
\hline Controle $\mathrm{x}$ tratamentos & s $* *$ & $*$ & $*$ & $* *$ \\
\hline LI x LA & $*$ & $\mathrm{~ns}$ & $* *$ & $* *$ \\
\hline LI x PC & ns & $* *$ & $* *$ & $* *$ \\
\hline $\mathrm{LA} \times \mathrm{PC}$ & $* *$ & & $\mathrm{~ns}$ & ns \\
\hline
\end{tabular}

${ }^{(1)}$ Coeficientes dos contrastes ortogonais: LIxLA (Co, 0; LI 1\%, 1; LI 2\%, 1; LI $3 \%, 1$; LA $1 \%,-1$; LA $2 \%,-1$; LA 3\%, -1; PC 0,1\%, 0; PC 0,2\%, 0; PC $0,3 \%, 0)$; LIxPC (Co, 0; LI 1\%, 1; LI 2\%, 1; LI $3 \%, 1$; LA $1 \%, 0$; LA $2 \%, 0$; LA $3 \%, 0$; PC $0,1 \%,-1$; PC $0,2 \%,-2$; PC $0,3 \%,-3)$; LAxPC (Co, 0 ; LI $1 \%, 0$; LI $2 \%, 0$; LI $3 \%, 0$; LA $1 \%, 1$; LA $2 \%, 1$; LA $3 \%, 1$; PC $0,1 \%,-1$; PC $0,2 \%,-1 ;$ PC $0,3 \%,-1)$. ns Não-significativo. * e **Significativo a 5 e $1 \%$ de probabilidade pelo teste $\mathrm{F}$, respectivamente.
Esses resultados estão de acordo com os encontrados por Li \& Gatlin (2003), quando avaliaram a suplementação de levedura de cerveja íntegra em rações para o híbrido de "striped bass". Os peixes alimentados com 1 e $2 \%$ de levedura íntegra obtiveram GP $20 \%$ superior, quando comparado aos que receberam a ração basal.

Em experimento comparando dois tipos de levedura, íntegra e parcialmente autolisada, Li \& Gatlin (2004) observaram que, após sete semanas de período experimental, os peixes alimentados com esses produtos, em níveis de 1 e $2 \%$ geralmente apresentaram maior GP em relação à ração basal e os peixes que receberam ração com levedura autolisada apresentaram tendência de maior GP. Esse resultado concorda com o encontrado neste trabalho, no qual a suplementação de LA proporcionou melhores respostas de GP e em que o nível ótimo estimado se apresentou próximo aos melhores níveis, 1 a $2 \%$, encontrado por esses autores.

Em estudo comparando a suplementação de diferentes leveduras (Saccharomyces cerevisiae, Phaffia rhodozyma, levedura experimental-HPPR1 e $\beta$-glucano) em juvenis de Litopenaeus vannamei, Scholz et al. (1999) verificaram que não houve diferença no peso final dos animais dos diferentes tratamentos. No entanto, quando se considerou a biomassa final, houve diferença significativa para o tratamento contendo $P$. rhodozyma em relação aos alimentados com $\beta$-glucano.

A suplementação de levedura e derivados proporcionou tendência de melhor GP em relação ao tratamento controle (Tabela 2). Em razão da composição da levedura e da forma de utilização dos seus derivados, estes apresentaram efeitos benéficos aos peixes.

Durante o período experimental não houve mortalidade. Tanto a suplementação de levedura íntegra (Ortuño et al., 2002; Li \& Gatlin, 2003) quanto a de levedura autolisada ( $\mathrm{Li}$ \& Gatlin, 2004), $\beta$ 1,3 glucanos derivados da parede celular de levedura (Sakai et al., 2001), nucleotídeos (Sakai et al., 2001; Li et al., 2004) e combinação entre glucanos e mananos (Miles et al., 2001) aumentam a resposta imune de peixes, e essa melhor condição de higidez pode proporcionar índices de desempenho produtivo superiores em relação aos animais não suplementados com levedura e derivados.

Foram observadas diferenças significativas $(\mathrm{p}<0,05)$ para tratamento dos valores médios de consumo de ração aparente $(\mathrm{C})$, quando submetidos à análise de variância (Tabela 2). O desdobramento dos graus de liberdade de tratamentos, por contrastes ortogonais entre totais de tratamentos (LI, LA e PC), revelou que houve diferença 
quanto ao consumo $(\mathrm{p}<0,01)$. Peixes que receberam as rações que continham LA ou LI apresentaram semelhantes respostas, e consumiram mais que os do grupo que receberam a ração contendo $\mathrm{PC}$.

$\mathrm{Na}$ avaliação do consumo a partir dos diferentes níveis de inclusão de LI na ração, pode-se observar efeito polinomial quadrático $(\mathrm{p}<0,05)$ expresso pela equação $\mathrm{Y}=78,60+20,39 \mathrm{x}-5,20 \mathrm{x}^{2}\left(\mathrm{R}^{2}=0,84\right)$, com maior consumo obtido pela inclusão de $1,96 \%$ de LI.

A diferença no consumo a partir da inclusão de LA na ração revelou efeito polinomial quadrático $(\mathrm{p}<0,01)$ expresso pela equação $Y=81,94+15,91 x-4,55 x^{2}\left(R^{2}=0,65\right)$, com o maior consumo estimado, apresentado pela inclusão de $1,75 \%$ de LA na ração.

No consumo de ração, de modo semelhante ao verificado quanto ao ganho de peso, a inclusão dos diferentes níveis de $\mathrm{PC}$ à ração não resultou em diferenças significativas ( $>>0,05)$. Porém, pode-se observar que, em relação ao controle, peixes alimentados com rações contendo $0,1,0,2$ e $0,3 \%$ de PC apresentaram tendência em aumentar o consumo.

A levedura possui características positivas que estimulam o peixe a se alimentar. Essas respostas confirmam a pesquisa realizada com a tilápia-do-nilo por Pereira-da-Silva $\&$ Pezzato (2000). Estes autores compararam a atratividade e a palatabilidade da LI com diversos ingredientes alimentares, sendo a LI classificada como de média atratividade, quando comparada ao ovo e à farinha de peixe. No entanto, a LI apresentou ótima atratividade e palatabilidade, quando comparada ao controle, recomendando sua inclusão às rações para peixes pela tendência positiva ao comportamento alimentar.

Gaiotto (2005) observou que juvenis de pintado Pseudoplatystoma corruscans alimentados com rações contendo 2,5 e $5 \%$ de LI e LA, de maneira geral, apresentaram maior consumo em relação ao tratamentocontrole e o suplementado com os mesmos níveis de PC. Segundo o autor, essa diferença pode estar relacionada ao teor de ácidos nucléicos na PC, que podem provocar prejuízos na metabolização da proteína verdadeira.

Os efeitos estimulatórios sobre as respostas alimentares de organismos aquáticos têm sido amplamente estudados com a avaliação de aminoácidos sintéticos livres ou uma mistura de aminoácidos. A levedura e derivados do seu processamento possuem quantidades satisfatórias de aminoácidos neutros, básicos e ácidos que podem conferir potencial atrato-palatabilizante.
A levedura possui alto teor em lisina que, além de se apresentar como limitante ao crescimento dos peixes (National Research Council, 1993), é classificado como aminoácido básico, que confere aumento da atividade alimentar em Tilapia zillii (Adams et al., 1988). Também contêm altas concentrações de ácido glutâmico e ácido aspártico, que podem proporcionar maior atratividade $\mathrm{e}$ palatabilidade em rações para algumas espécies de peixes. De acordo com Adams et al. (1988), quando se adicionou ácido glutâmico em alguns alimentos, houve estímulo para aumento da resposta alimentar em $T$. zilli.

Apesar da composição de ácidos nucléicos e nucleotídeos não terem sido avaliados neste estudo, alguns autores destacam que a levedura e seus derivados apresentam grande quantidade em ácidos nucléicos, representados principalmente pelo RNA. De acordo com Butolo (1997), a levedura apresenta elevado nível de nitrogênio não-protéico de 20 a $30 \%$, representado basicamente por ácidos nucléicos ( 8 a 12\% do nitrogênio total). Em trabalho sobre produção-piloto de derivados de levedura, a levedura íntegra apresentou 5,70\% do seu conteúdo total em RNA, a autolisada, 7,90\%, o extrato, $6,90 \%$ e a parede celular, $1,83 \%$ (Sgarbieri et al., 1999).

Os ácidos nucléicos são compostos por uma série de nucleotídeos, que são considerados estimuladores na alimentação de peixes, sendo a atividade de frações de nucleotídeos mais efetiva que a utilização de um grupo inteiro. Segundo Mackie \& Adron (1978), a suplementação de inosina apresentou resultados positivos em rações para "turbot" Scophtalmus maximus.

A somatória entre as diferentes proporções e quantidades de aminoácidos e nucleotídeos de cada produto de levedura pode ter conferido maior atratopalatabilidade das rações suplementadas em relação ao controle, uma vez que esse tratamento, quando comparado aos tratamentos contendo levedura e derivados, apresentou tendência de menor consumo de ração.

Os valores médios de conversão alimentar aparente (CA), quando submetidos à análise de variância, apresentaram diferenças significativas $(\mathrm{p}<0,05)$ para tratamentos (Tabela 2). O desdobramento dos graus de liberdade de tratamentos formado pelos contrastes ortogonais revelou que a LA proporcionou melhores índices de CA que a $\mathrm{LI}(\mathrm{p}<0,01)$, e que a CA das rações que continham PC foi melhor que as das rações com LI $(\mathrm{p}<0,01)$. As rações contendo LA e a PC proporcionaram CA semelhante, estatisticamente, sendo ambas superiores aos tratamentos suplementados com LI. 
Os animais que receberam rações suplementadas com diferentes níveis de LI não apresentaram diferença significativa na CA. A levedura apresenta parede celular bastante espessa, que pode representar até $30 \%$ da MS total, relativamente resistente à degradação pelo trato gastrintestinal, enzimas e bactérias, o que pode ter prejudicado a eficiência de utilização das rações suplementadas com LI, piorando a conversão alimentar.

Peixes alimentados com as rações que continham os diferentes níveis de LA apresentaram diferentes respostas de CA $(p<0,05)$. Esta diferença a partir da inclusão dos diferentes níveis de LA na ração, revelou efeito polinomial quadrático $(\mathrm{p}<0,05)$ expresso pela equação $\mathrm{Y}=1,28-0,12 \mathrm{x}+0,04 \mathrm{x}^{2}\left(\mathrm{R}^{2}=0,78\right)$, com o melhor índice de CA apresentado pela inclusão de 1,38\% de LA na ração.

As respostas observadas refletem os resultados de GP e de consumo. A LA proporcionou as melhores respostas de GP a partir de um consumo maior, mas com melhor CA. O produto autolisado consiste no total de células lisadas, componentes solúveis e insolúveis, que, em razão do rompimento da parede celular, poderiam estar mais disponíveis e melhorar a eficiência de utilização das rações.

Os tratamentos suplementados com PC não apresentaram diferença para a CA $(p>0,05)$. $\mathrm{O}$ alto conteúdo de polissacarídeos não-amiláceos presente na parede celular pode afetar o aproveitamento de nutrientes de uma ração. No entanto, os resultados para essa variável indicam que os níveis de suplementação utilizados não foram suficientes para ocasionar tais efeitos prejudiciais.

Li \& Gatlin (2004), ao comparar a suplementação de levedura íntegra e parcialmente autolisada, observaram que a eficiência alimentar dos peixes alimentados com rações contendo o produto autolisado em níveis de 1 e $2 \%$ foram significativamente $(p<0,05)$ melhores que a ração controle. Por sua vez, Scholz et al. (1999) não observaram diferenças significativas na CA de juvenis de L. vannamei, que receberam rações suplementadas com diferentes leveduras e $\beta$-glucano.

Os valores médios da taxa de eficiência protéica (TEP), quando submetidos à análise de variância, revelaram diferenças significativas $(\mathrm{p}<0,01)$ para tratamentos (Tabela 2). O desdobramento dos graus de liberdade de tratamentos revelou que a TEP dos peixes que receberam as rações contendo LI diferiu $(\mathrm{p}<0,01)$ daquelas cujas rações continham LA e PC. Entretanto, não houve diferença na TEP $(p>0,05)$ entre o grupo que recebeu LA e PC.

A diferença na TEP pela inclusão de LA na ração revelou efeito polinomial quadrático $(\mathrm{p}<0,01)$ expresso pela equação $Y=2,40+0,21 x-0,08 x^{2}\left(R^{2}=0,71\right)$, com este melhor parâmetro, estimado pela inclusão de $1,30 \%$ de LA na ração. As TEP dos grupos cujos peixes foram alimentados com as rações contendo os diferentes níveis de LI e PC não apresentaram diferenças $(p>0,05)$ (Tabela 2).

As respostas da TEP corroboram os resultados obtidos por Li \& Gatlin (2003), que utilizaram levedura de cerveja em dietas para o híbrido de "striped bass" em níveis crescentes (1;2 e 4\% da dieta) e observaram, em dois experimentos, melhora na eficiência alimentar nos peixes alimentados com as dietas suplementadas com levedura.

Com base nos resultados apresentados para as diferentes variáveis de desempenho produtivo, pode-se constatar, entre totais de tratamento, que a suplementação de LA proporcionou melhores respostas de GP e CA, quando comparados a LI e PC, e que, entre os níveis ótimos estimados pela equação de regressão para LA, obteve-se valores entre 1,30 a 1,75\% (Tabela 2).

Os valores de U, PB, EE e MM de filés de juvenis de tilápia não apresentaram diferenças significativas pelos contrastes estudados (Tabela 3). Peixes alimentados com as rações suplementadas com levedura e seus derivados apresentaram composição químicobromatológica semelhante para filé.

Para a composição em PB, não houve diferença entre as médias dos diferentes níveis de inclusão de LI e LA (Tabela 3), no entanto, quando se considera a PC, constata-se efeito polinomial linear $(\mathrm{p}<0,05)$, expresso pela equação $Y=16,41-3,39 x\left(R^{2}=0,36\right)$, ou seja, à medida que se aumentou à suplementação de $\mathrm{PC}$, houve diminuição do teor protéico no filé.

Quando se considerou o teor de EE nos filés dos peixes, pôde-se observar que a inclusão dos diferentes níveis de LI, LA e PC não resultou em diferenças significativas (Tabela 3). A composição em MM demonstrou efeito polinomial linear $(p<0,05)$ nos tratamentos LI e PC, com as respectivas equações $\mathrm{Y}=1,16-0,053 \mathrm{x}\left(\mathrm{R}^{2}=0,60\right)$ e $\mathrm{Y}=1,12-0,43 \mathrm{x}$ $\left(\mathrm{R}^{2}=0,51\right)$ e com melhores valores de MM pela inclusão de 0,57 e $0,3 \%$, respectivamente. Na suplementação de LA, não foram observadas diferenças significativas.

Com base na composição química dos filés dos peixes, verificou-se que a utilização de LI, LA e PC não 
proporcionou grandes alterações em sua composição. Estes resultados são importantes, se consideradas as respostas de GP, CA e TEP, quando diferenças foram constatadas, indicando a ação positiva da suplementação desses microingredientes, sem alterar negativamente a composição dos filés.

O conhecimento da composição corporal dos peixes fornece informações para a determinação dos níveis adequados de substituição de ingredientes numa dieta. Dabrowski et al. (1980) alimentaram alevinos de trutaarco-íris com levedura de petróleo e constataram que os peixes arraçoados com biomassa de levedura apresentaram conteúdo corporal de PB e teores de

Tabela 3. Composição média quanto à umidade (U), proteína bruta (PB), extrato etéreo (EE) e matéria mineral (MM) dos filés de tilápia-do-nilo alimentada com rações suplementadas com diferentes níveis levedura íntegra (LI), levedura autolisada (LA) e parede celular (PC) ${ }^{(1)}$.

\begin{tabular}{|c|c|c|c|c|}
\hline Fonte de variação & $\mathrm{U}(\%)$ & $\mathrm{PB}(\%)$ & $\mathrm{EE}(\%)$ & MM (\%) \\
\hline & \multicolumn{4}{|c|}{ Levedura íntegra } \\
\hline Controle & 81,64 & 16,39 & 0,98 & 1,12 \\
\hline LI $1 \%$ & 82,21 & 16,09 & 0,92 & 1,16 \\
\hline LI $2 \%$ & 82,57 & 15,78 & 0,88 & 1,05 \\
\hline LI 3\% & 82,62 & 15,60 & 1,00 & 0,98 \\
\hline Teste F & ns & $\mathrm{ns}$ & $\mathrm{ns}$ & $*$ \\
\hline \multirow[t]{2}{*}{$\mathrm{CV}(\%)$} & 1,24 & 4,22 & 8,96 & 5,68 \\
\hline & \multicolumn{4}{|c|}{ Levedura autolisada } \\
\hline Controle & 81,64 & 16,39 & 0,98 & 1,12 \\
\hline LA $1 \%$ & 82,15 & 16,18 & 0,82 & 1,08 \\
\hline LA $2 \%$ & 82,84 & 15,42 & 0,90 & 1,04 \\
\hline LA $3 \%$ & 82,10 & 15,97 & 1,11 & 1,05 \\
\hline Teste F & $\mathrm{ns}$ & $\mathrm{ns}$ & ns & $\mathrm{ns}$ \\
\hline \multirow[t]{2}{*}{$\mathrm{CV}(\%)$} & 0,88 & 2,65 & 32,26 & 4,60 \\
\hline & \multicolumn{4}{|c|}{ Parede celular } \\
\hline Controle & 81,64 & 16,39 & 0,98 & 1,12 \\
\hline PC $0,1 \%$ & 81,44 & 16,41 & 1,29 & 1,08 \\
\hline PC $0,2 \%$ & 82,82 & 15,12 & 1,37 & 1,00 \\
\hline PC $0,3 \%$ & 82,39 & 15,69 & 1,20 & 1,00 \\
\hline Teste F & ns & $*$ & $\mathrm{~ns}$ & $\mathrm{~ns}$ \\
\hline $\mathrm{CV}(\%)$ & 0,99 & 2,48 & 30,48 & 5,28 \\
\hline \multicolumn{5}{|c|}{ Teste $\mathrm{F}$} \\
\hline Controle $\mathrm{x}$ tratamentos & s ns & ns & ns & ns \\
\hline LI x LA & ns & ns & ns & ns \\
\hline LI x PC & ns & $\mathrm{ns}$ & ns & ns \\
\hline LA x PC & ns & ns & ns & ns \\
\hline \multicolumn{5}{|c|}{ 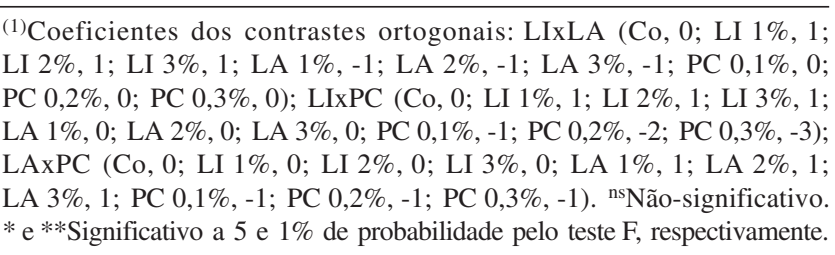 } \\
\hline
\end{tabular}

MM mais elevados, bem como teores mais baixos de EE que o do grupo-controle. Resultados semelhantes foram constatados por Martin et al. (1993), quando forneceram a esta mesma espécie dietas com níveis de 0,25 e $35 \%$ de levedura de petróleo e também observaram níveis mais elevados de PB e MM nas carcaças dos peixes que receberam os maiores níveis de levedura. Rumsey et al. (1992) não constataram diferenças nos teores de PB e EE corporal de trutaarco-íris alimentada com dietas contendo níveis crescentes de levedura de álcool $(0,7,5,20,30$ e 50\%).

Li \& Gatlin (2003) observaram que a suplementação de LI, em níveis de suplementação próximos ao utilizado neste trabalho, não afetou significativamente a composição químico-bromatológica de carcaças do híbrido de "striped bass". Gaiotto (2005) observou que, em juvenis de pintado, suplementados com 2,5 e 5\% de LI, LA e PC, praticamente não houve alteração nos teores de nutrientes corporais no início e após o experimento de alimentação com essas dietas.

\section{Conclusões}

1. A suplementação de levedura e derivados em rações para alevinos de tilápia-do-nilo melhora o desempenho produtivo, sem alterações na composição do filé.

2. Entre os microingredientes avaliados, a levedura autolisada proporciona desempenho superior, quando utilizada entre 1,30 e $1,59 \%$.

\section{Agradecimentos}

À Usina Santo Antônio S.A., à ICC Com. Export. Import. Ltda., e à Supre Mais Produtos Bioquímicos Ltda., pelo apoio.

\section{Referências}

ADAMS, M.A.; JOHNSEN, P.B.; ZHOU, H.G. Chemical enhancement of feeding for the herbivorous fish Tilapia zillii. Aquaculture, v.72, p.95-107, 1988.

ASSOCIATION OF OFFICIAL ANALYTICAL CHEMISTS AOAC. Official methods of analysis of the Association of Official Analytical Chemists. 15 ${ }^{\text {th }}$ ed. Arlington: AOAC, 1990. BUTOLO, J.E. Uso da levedura desidratada na alimentação de aves. In: SIMPÓSIO SOBRE TECNOLOGIA DA PRODUÇÃO E UTILIZAÇÃO DA LEVEDURA DESIDRATADA NA ALIMENTAÇÃO ANIMAL, 1997, Campinas. Anais. Campinas: CBNA, 1997. p.51-83. 
DABROWSKI, K.; HASSARD, S.; QUINN, J.; PITCHER, T.J.; FLINN, A.M. Effect of Geotrichum canidum protein substitution in pelleted fish feed on the growth of rainbow trout (Salmo gairdneri Rich.) and on utilization of the diet. Aquaculture, v.21, p.213-232, 1980.

GAIOTTO, J.R. Utilização de levedura de cana-de-açúcar (Saccharomyces cerevisiae) e seus subprodutos na alimentação de juvenis de pintado (Pseudoplatystoma corruscans). 2005. 87p. Dissertação (Mestrado) - Universidade de São Paulo, Pirassununga.

GONÇALVES, G.S. Fitase na digestibilidade aparente de alimentos vegetais pela tilápia do Nilo (Oreochromis niloticus). 2003. 72p. Dissertação (Mestrado) - Universidade Estadual Paulista, Botucatu.

HISANO, H. Levedura desidratada íntegra, autolisada e parede celular como pró-nutrientes para tilápia do Nilo. 2005. 94p. Tese (Doutorado) - Universidade Estadual Paulista, Botucatu.

HISANO, H.; PEZZATO, L.E.; BARROS, M.M.; FREIRE, E.S.; GONÇALVES, G.S.; FERRARI, J.E.C. Zinco e levedura desidratada de álcool como pró-nutrientes para alevinos de tilápia do Nilo (Oreochromis niloticus). Acta Scientiarum - Animal Sciences, v.26, p.171-179, 2004.

LI, P.; GATLIN, D.M. Dietary brewers yeast and the prebiotic Grobiotic ${ }^{\mathrm{TM}} \mathrm{E}$ influence growth performance, immune responses and resistance of hybrid striped bass (Morone chrysops $\mathrm{x}$ M. saxatilis) to Streptococcus iniae infection. Aquaculture, v.231, p.445-456, 2004.

LI, P.; GATLIN, D.M. Evaluation of brewers yeast (Saccharomyces cerevisiae) as feed supplement for hybrid striped bass (Morone chrysops x M. saxatilis). Aquaculture, v.219, p.681-692, 2003.

LI, P.; LEWIS, D.H.; GATLIN, D.M. Dietary oligonucleotides from yeast RNA influence immune responses and resistance of hybrid striped bass (Morone chrysops x Morone saxatilis) to Streptococcus iniae infection. Fish and Shellfish Immunology, v.16, p.561-569, 2004.

MACKIE, A.M.; ADRON, J.W. Identification of inosine and inosine 5 -monophosohate as the gustatory feeding stimulant for turbot Scophtalmus maximus. Comparative Biochemistry and Physiology, v.60, p.79-83, 1978.

MARTIN, A.M.; GODDARD, S.; BEMISTER, P. Production of Candida utilis as aquaculture feed. Journal of Science Food and Aquaculture, v.61, p.363-370, 1993.

MILES, D.J.C.; POLCHANA, J.; LILLEY, J.H.; KANCHANAKHAN, S.; THOMPSON, K.D.; ADAMS, A. Immunostimulation of striped snakehead Channa striata against epizootic ulcerative syndrome. Aquaculture, v.195, p.1-15, 2001.
MULDER, R.W.A.W. The use of the probiotics in food-animal practice. Veterinary Medicine, v.88, p.282-288, 1993.

NATIONAL RESEARCH COUNCIL (Estados Unidos). Committee on Animal Nutrition. Nutrient requirements of fish. Washington, DC: National Academic Press, 1993. 115p.

ORTUÑO, J.; CUESTA, A.; RODRÍGUEZ, A.; ESTEBAN, M.A.; MESEGUER, J. Oral administration of yeast, Saccharomyces cerevisiae, enhaces the cellular inate immune response of gilthead seabream (Spaurus auratus L.). Veterinary Immunology and Immunopathology, v.85, p.41-50, 2002.

PEREIRA-DA-SILVA, E.M.; PEZZATO, L.E. Respostas da tilápia do Nilo (Oreochromis niloticus) à atratividade e palatabilidade de ingredientes utilizados na alimentação de peixes. Revista Brasileira de Zootecnia, v.29, p.1273-1280, 2000.

PEZZATO, L.E.; MIRANDA, E.C.; BARROS, M.M.; QUINTERO-PINTO, G.; FURUYA, W.M.; PEZZATO, A.C. Digestibilidade aparente de ingredientes pela tilápia do Nilo (Oreochromis niloticus). Revista Brasileira de Zootecnia, v.31, p.1595-1604, 2002.

POPMA, T.J.; GREEN, B.W. Aquacultural production manual: sex reversal of tilapia in earthen ponds. Auburn: Auburn University, International Center for Aquaculture, 1990. 15p.

RUMSEY, G.L.; WINFREE, R.A.; HUGHES, S.G. Nutritional value of dietary nucleic acid and purine bases to rainbow trout (Oncorhynchus mykiss). Aquaculture, v.108, p.97-110, 1992.

SAKAI, M.; TANIGUCHI, K.; MAMOTO, K.; OGAWA, H.; TABATA, M. Immunoestimulant effects of nucleotide isolated from yeast RNA on carp, Cyprinus carpio L. Journal of Fish Disease, v.24, p.433-438, 2001.

SAS INSTITUTE. SAS user's guide statistics. $5^{\text {th }}$ ed. Cary: SAS Institute, 1985. 956p.

SCHOLZ, U.; GARCIA-DIAZ, G.; RICQUE, D.; CRUZ SUAREZ, L.E.; VARGAS-ALBORES F.; LATCHFORD J. Enhancement of vibriosis resistance in juvenile Penaeus vannamei by supplementation of diets with different yeasts products. Aquaculture, v.176, p.271-283, 1999.

SGARBIERI, V.C.; ALVIM, I.D.; VILELA, E.S.D. Produção piloto de derivados de levedura (Saccharomyces sp.) para uso como ingredientes na formulação de alimentos. Brazilian Journal of Food Technology, v.2, p.119-125, 1999.

STELL, R.G.D.; TORRIE, S.H. Principles and procedures of statistics: a biometrical approach. $2^{\text {nd }}$ ed. Auckland: McGraw-Hill International, 1984. 633p. 